\title{
COLOMBIA 2008: ÉXITOS, PELIGROS Y DESACIERTOS DE LA POLÍTICA DE SEGURIDAD DEMOCRÁTICA DE LA ADMINISTRACIÓN URIBE
}

\author{
Colombia 2008: Success, Dangers and Mistakes of the Policy \\ of Democratic Security in the Uribe Administration
}

\section{MÓNICA PACHÓN*}

Universidad de los Andes, Colombia

\begin{abstract}
RESUMEN
De la misma manera que el 2007, el año 2008 se caracterizó por grandes contrastes. Por un lado, el gobierno de Álvaro Uribe Vélez logró grandes éxitos militares en su política de seguridad democrática, debilitando la estructura organizacional de las FARC y mejorando todos los indicadores agregados de violencia, con grandes avances en el drama de los secuestrados. Sin embargo, los escándalos por mal comportamiento de agentes del Estado cuestionan el compromiso "democrático" del gobierno. Los debates sobre una tercera reelección mantienen el ambiente de incertidumbre ante un posible tercer mandato.
\end{abstract}

Palabras clave: Política de seguridad democrática, Colombia, reelección, FARC, Álvaro Uribe Vélez.

\begin{abstract}
Comparable to what happened in 2007, the year 2008 was marked by large contrasts. On the one hand, Uribe's administration executed unrivaled military successes consolidating his policy of Democratic Security by debilitating the organization structure of the FARC and improving all violence indicators -with remarkable success in the kidnapping drama-. However, in the downside, numerous scandals resulting from questionable behavior of state agents resulted in a very negative evaluation of the democratic compromise of the government. Political uncertainty reigns due to the possibility of a third reelection.
\end{abstract}

Key words: Policy of Democratic Security, Colombia, reelection, FARC, Álvaro Uribe Vélez.

* Agradezco la ayuda y retroalimentación de Orlando Gracia y Andrea Cheer para la elaboración del documento; a Elisabeth Ungar por facilitarme la información de parapolítica en el Congreso, y a Natalia Perozzo por su apoyo en la asistencia de investigación. También agradezco a David Altman y a los evaluadores anónimos del artículo por sus detallados comentarios. 


\section{URIBE: SEGUNDO PERÍODO, SEGUNDO AÑO}

El 2008 será recordado como un año de grandes contrastes, representativos de lo que ha sido la segunda administración del Presidente Álvaro Uribe Vélez. En primer lugar, se recogen los frutos de la inversión de inteligencia en el ejército con éxitos militares en la lucha contra la insurgencia armada, sin precedentes en la historia del país. Y, al mismo tiempo, se continúan destapando grandes cuestionamientos en los procedimientos empleados para llegar a esos resultados. Los escándalos de los homicidios por agentes del Estado ocupan la primera página de los diarios del país y se convierten en la evidencia más macabra de las consecuencias del conflicto interno en Colombia.

En materia política, el congreso sigue siendo sujeto de controversias por los escándalos de la "parapolítica", presentes desde el año 2006 (Botero, 2007). Al final del año, 30 congresistas habían sido condenados por sus nexos con grupos paramilitares y a más de 70 se les habría comenzado un expediente, quienes en su mayoría hacían parte de la coalición de gobierno.

La popularidad del presidente y el esfuerzo de la coalición mayoritaria hacen posible la colecta de firmas necesarias para un referendo que materialice la posibilidad de cambiar la Constitución para una tercera reelección. Siguen presentes los cuestionamientos acerca del compromiso del gobierno colombiano con las víctimas de desplazamiento y del conflicto, los cuales pasan algo desapercibidos en la opinión pública, por las derrotas militares que la dominan.

A continuación se discuten los hechos más importantes que marcaron la dinámica política, económica y social del país en el año 2008.

\section{TEMAS SALIENTES DE LA REALIDAD NACIONAL Y SU IMPACTO POLÍTICO}

\section{Coyuntura Política}

\section{a. Avances en la consolidación de la Política de Seguridad Democrática}

El conflicto armado en Colombia ha sido una constante en los últimos 50 años de historia. En las últimas dos décadas la intensidad del conflicto y la presencia de grupos al margen de la ley en el territorio se ha intensificado, siendo principales protagonistas las FARC, el ELN y los grupos de autodefensa. Como afirma Botero (2008), el narcotráfico es sin duda el gran catalizador del incremento de la violencia política, ya que, entre otras cosas, se convierte en fuente importante de recursos que permite la financiación de la guerra. Desde la década de los ochenta, los gobiernos han oscilado en la forma como se enfrenta el conflicto en un péndulo que va desde una estrategia de diálogo y la negociación hasta la represión. En la década de los noventa, y como resultado del crecimiento de las FARC y las derrotas militares ocurridas en el gobierno Samper (1994-1998), el presidente electo Andrés Pastrana, optó por una estrategia de negociación con las FARC, que fracasó en su propósito. Adicionalmente a los niveles de frustración por el rompimiento de 
negociaciones en la última fase de su gobierno, se sumaron los incrementos en los niveles de violencia y continuos enfrentamientos entre las fuerzas paramilitares (Autodefensas Unidas de Colombia) y las fuerzas guerrilleras. Otros indicadores como el número de secuestros individuales y masivos aumentaron, dejando en la ciudadanía la sensación de que el Estado era incapaz de responder ante la amenaza de las FARC.

En este contexto, el liberal disidente Álvaro Uribe Vélez, candidato por el Partido Primero Colombia, fue elegido con una plataforma política en la que propuso fortalecer al Estado y especialmente al ejército para combatir las fuerzas guerrilleras y así disminuir su capacidad bélica y mejorar los indicadores de seguridad. Se establecieron igualmente como requisito para cualquier negociación el cese a las hostilidades y el fin de acciones terroristas. La política de seguridad democrática, nombre que acuñó para su programa de gobierno, ha sido una de las políticas que el presidente Uribe ha implementado con mayor continuidad. Aunque sus métodos han sido altamente cuestionados (i.e. redes de informantes civiles y desmovilización de los paramilitares), lo cierto es que la disminución de homicidios, el número de ataques de las FARC y el ELN, así como el número de secuestros consolidó a Uribe como uno de los presidentes con mayores niveles de popularidad. Esto fue posible, en parte, por el aumento del pie de fuerza que comenzó en su primer periodo, y que sumó más de 100.000 uniformados adicionales entre fuerzas militares y policía (Ver Gráfica 1). La aprobación de la reelección del presidente en el año 2005 le abrió el camino para su segundo periodo, en el cual el presidente propuso comenzar la fase de consolidación de la política de seguridad ciudadana, en la cual la recuperación del control territorial se complementaría con presencia institucional permanente (Botero, 2008).

Gráfica 1: Evolución del Pie de Fuerza en miles de Uniformados, 2002-2008

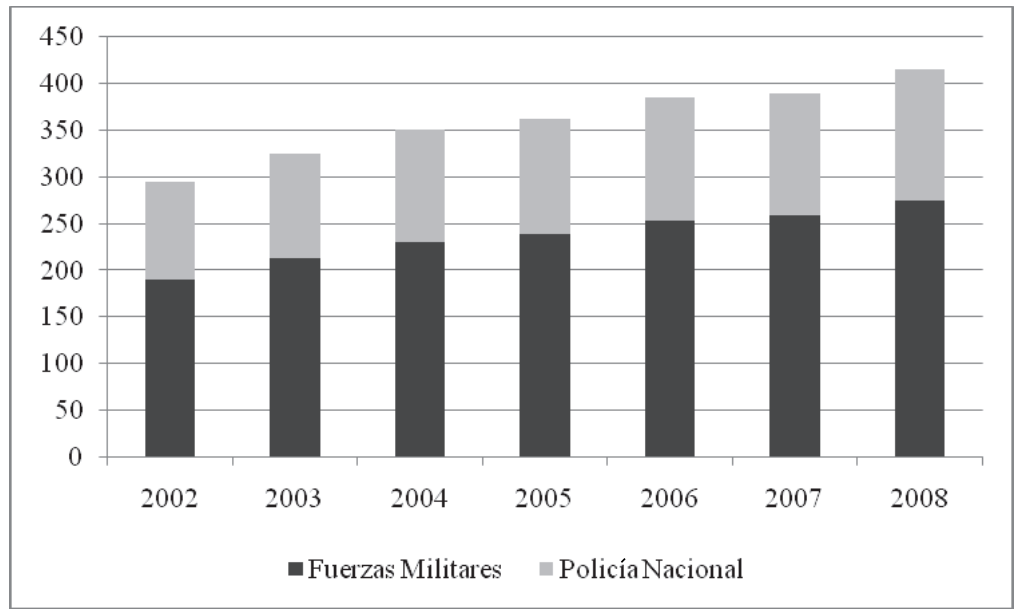

Fuente: DNP. Plan Nacional de Desarrollo "Estado Comunitario: Desarrollo para todos" Balance de Resultados 2008. 
A pesar de que la disminución en los niveles de violencia era significativa -y el número de bajas por parte de la guerrilla aumentaba-, el gobierno había tenido menos éxito en atacar la cúpula de la organización de las FARC. En el 2007, algunos de los jefes de frentes e importantes cabecillas fueron dados de baja, incluyendo uno de los miembros del Estado Mayor, cúpula máxima de las FARC (Botero, 2008). Pero la situación no parecía mejorar en términos cualitativos, puesto que a pesar de estos logros, muchos secuestrados permanecían en cautiverio y sin mayor esperanza de ser rescatados. Las noticias y advertencias sobre el estado de salud de algunos de los secuestrados requerían algún tipo de reacción de parte del gobierno.

Ante la presión y el descenso de los niveles de aprobación, el gobierno decidió cambiar su posición y delegar las negociaciones de intercambio de prisioneros en manos del Presidente Chávez y la Senadora liberal Piedad Córdoba, quienes se habrían ofrecido en agosto del 2007 a realizar los acercamientos con la cúpula de las FARC para la liberación de los secuestrados por medio de un acuerdo humanitario, siempre y cuando se respetaran los canales diplomáticos colombianos. Aunque se lograron algunos acercamientos entre las FARC, el Presidente Chávez y la Senadora Piedad Córdoba, que fueron altamente celebrados por la comunidad internacional (en especial, por el gobierno francés), Uribe decide sorpresivamente retirar esta función al Presidente Chávez al tener conocimiento de una comunicación directa de éste con el Comandante de Ejército, el General Mario Montoya. A su turno, el Presidente Chávez decidió congelar las relaciones con Colombia, por considerar injustificada la decisión del Presidente Uribe.

La presión de la comunidad internacional para que el gobierno colombiano reconsiderara la medida no se hizo esperar, especialmente después de las pruebas de supervivencia de varios de los secuestrados en muy grave estado de salud. A raíz de esta nueva información, el presidente propuso una zona de neutralidad para hacer el intercambio de prisioneros guerrilleros por la entrega de algunos de los secuestrados con la autorización de la creación de una misión humanitaria (Ver Botero, 2008). Este evento terminó en la operación Emmanuel, en la cual las FARC -quienes prometieron la entrega de Consuelo González, Clara Rojas y su hijo Emmanuel- terminan muy mal libradas al revelar el gobierno, que Emmanuel no estaba en manos de las FARC sino en un hogar de Bienestar Familiar (Botero, 2008). Aunque posteriormente se da la liberación de Clara Rojas y Consuelo González, el costo de credibilidad para las FARC fue significativo.

A partir de enero del 2008 la seriedad y el compromiso de las FARC fueron cuestionados por la opinión pública nacional e internacional y el gobierno recuperó sus niveles de aprobación con respecto al manejo del conflicto con la guerrilla (Gráfica 1). El desprecio por las acciones de las FARC no sólo se concretó en mejoras en los niveles de popularidad, sino en impresionantes despliegues de acción colectiva en marchas pacíficas en el territorio nacional. Sorprendentemente, la primera marcha convocada y organizada desde Facebook ${ }^{1}$ por ciudadanos sin adscripción política -logró que más de 10 millones

1 Red social en internet, www.facebook.com. Otras marchas se dieron en marzo, julio y noviembre para pedir por la liberación de los secuestrados. 
de colombianos salieran a las calles el 4 de febrero para repudiar el secuestro y las demás estrategias utilizadas por las FARC. ${ }^{2}$

Gráfica 2: ¿Usted aprueba o desaprueba la forma en que el presidente está manejando la guerrilla?

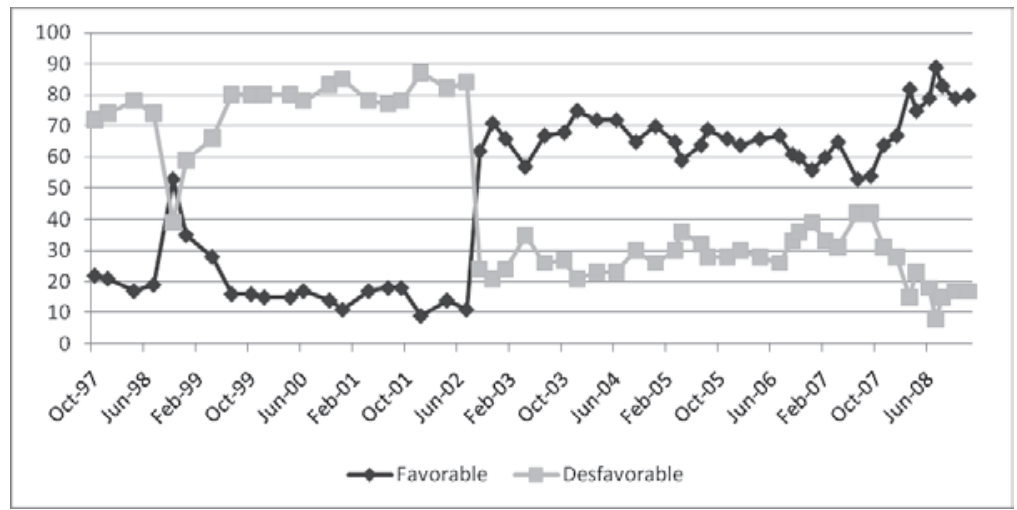

Fuente: Gallup.

Las FARC, para no perder el momentum establecido con las liberaciones previas y reiterar el rol del Presidente Hugo Chávez y la senadora Piedad Córdoba, continuaron con las entregas unilaterales de algunos de los "canjeables". ${ }^{3}$ El 28 de febrero fueron liberados cuatro ex congresistas que llevaban más de 6 años secuestrados: Jorge Eduardo Gechem, Luis Eladio Pérez, Gloria Polanco y Orlando Beltrán Cuéllar. Inmediatamente después de ser liberados, éstos lanzaron fuertes críticas por la obstinación del Presidente Uribe en no ceder al intercambio humanitario. En sus declaraciones, algunos de los liberados -quienes habrían sido compañeros de cautiverio de Ingrid Betancourt- advirtieron de su pésimo estado de salud, que aumentaba la presión sobre el gobierno: La comunidad internacional tenía sus ojos puestos en su pronta liberación. El que no se avanzara en torno a un acuerdo humanitario disminuía la probabilidad de su liberación mientras estuviera viva. ${ }^{4}$ Igualmente, los testimonios de los liberados confirmaban la presencia de frentes de las FARC en las zonas fronterizas con Ecuador.

2 Ocurrieron otras marchas durante el transcurso del año. En marzo se convocó a una marcha por la violación de derechos humanos -esta vez no sólo dirigida en protesta contra las FARC.

3 Los secuestrados "canjeables" son aquellos que las FARC podrían eventualmente, utilizar como moneda de intercambio por algunos de sus líderes presos.

4 Diario El Tiempo (29 de febrero del 2008) "Si el Presidente insiste en rescates militares va a recibir 40 o 50 cadáveres: Luis Eladio Pérez" [En línea]: http://www.eltiempo.com/archivo/documento/CMS-3979605 [Consulta: 20-04-2009]. "En rueda de prensa en Caracas, Pérez dijo anoche que van a trabajar de la mano del Presidente Hugo Chávez en una serie de acciones que permitan alcanzar la sensibilización del pueblo colombiano y de la comunidad internacional para presionar una solución política. "Señor Presidente Uribe, la solución es política. Si persiste en la terca necesidad de insistir en los rescates militares, señor Presidente Uribe, va a recibir 40 o 50 cadáveres de estos ciudadanos que llevan 10, 9, 8 y, en el caso de Íngrid, 6 años", dijo. 
En medio de la presión por el acuerdo humanitario, el ejército colombiano seguía acertando en su estrategia de atacar a los cabecillas de la organización. El 26 de febrero las autoridades capturaron a alias "Martín Sombra", quien comandaba el grupo que mantenía cautivos a los secuestrados americanos y era reconocido por su cercanía con alias "Tirofijo", el Comandante fundador de las FARC. El 1 de marzo, tan sólo unos días después de la liberación unilateral de los cuatro congresistas, el gobierno emitió un comunicado en el cual se confirmaba que el ejército, en una operación ocurrida a 1.800 metros de la frontera entre Ecuador y Colombia (en territorio ecuatoriano), habría dado de baja a Raúl Reyes, segundo al mando del Secretariado de las FARC. Así que en menos de tres meses, el Estado colombiano había logrado dar importantes golpes a la organización guerrillera que ponían en evidencia su vulnerabilidad. Raúl Reyes era el encargado de mantener contactos internacionales, cabeza visible durante el fallido proceso de paz y muy difícil blanco militar.

Las circunstancias de la muerte de Reyes dieron lugar a fuertes cuestionamientos por parte del Presidente ecuatoriano Rafael Correa y el Presidente Hugo Chávez, quienes consideraron la incursión del ejército colombiano en territorio ecuatoriano una abierta violación a su soberanía y acusaron al gobierno colombiano de haber cometido una masacre fuera de su territorio. A pesar de las críticas, el 83\% de la población respaldó el operativo. De nuevo, los familiares de los secuestrados se pronunciaron con reservas, puesto que consideraban que la operación rompía con la ilusión del pronto acuerdo humanitario creada con las liberaciones de carácter unilateral.

Otro golpe al Secretariado ocurrió ocho días después (marzo 8), cuando se informó que miembros del Frente 47 de las FARC habían dado de baja a su comandante, uno de los miembros más jóvenes del secretariado de las FARC -Iván Ríos-.$^{5}$ Así que, en menos de dos meses, las fuerzas militares habrían logrado golpes estratégicos a la estructura de las FARC.

Pero sin duda la hazaña militar más importante durante el 2008 fue la llamada operación Jaque, ocurrida el 2 de julio, en la cual se rescataron 15 secuestrados, entre los cuales estaban las fichas de negociación más fuertes de las FARC: tres contratistas americanos que llevaban más de cuatro años secuestrados (Marc Gonsalves, Keith Stansell y Thomas Howes) e Ingrid Betancourt (candidata a la presidencia en 2002). ${ }^{6}$ La operación Jaque fue dirigida por los generales Freddy Padilla y Mario Montoya, quienes de la mano con las fuerzas de inteligencia y la información obtenida de desertores de la guerrilla, lograron engañar a quienes eran encargados de la seguridad de los secuestrados. ${ }^{7}$ La operación, que logró completarse sin un solo disparo, consolidó la posición del Presidente Uribe frente

5 Como prueba, uno de los desertores le cortó una mano para que las autoridades pudieran constatar su identidad.

6 Los demás liberados eran militares y policías: William Pérez; Amaón Flórez; Erasmo Romero; José Miguel Arteaga; José Ricardo Marulanda; Juan Carlos Bermeo; Raimundo Malagón; Julio César Buitrago; Armando Castellanos; Vianey Javier Rodríguez Porras y Jairo Durán Puerto.

7 Para conocer más detalles de la operación, ver Diario El Tiempo (3 de julio de 2008) “Con Engaño de Caballo de Troya, Ejército rescató a los 15 rehenes". [En línea] http://www.eltiempo.com/archivo/documento/ MAM-2999143 [Consulta: 20-04-2009]. 
a la guerrilla, significándole un incremento en su popularidad del 9\% en las encuestas en tan sólo 5 días, en donde el 85\% de la población encuestada aprobó el manejo que el presidente le estaba dando al tema de la guerrilla. ${ }^{8}$

A raíz de estos eventos y los continuos programas apoyando la deserción de las filas de la guerrilla, el número de desertores individuales de todos los rangos incrementó. ${ }^{9}$ El 16 de mayo, alias "Karina", comandante del Frente 47, se entregó a las autoridades, demostrando la crisis al interior de las FARC. Otro caso ilustrativo fue el de alias "Isaza", guerrillero guardián del senador secuestrado Tulio Lizcano, quien huyó exitosamente con él, entregándose a las autoridades a finales de octubre. La siguiente gráfica muestra la evolución de las deserciones individuales por grupo, haciendo evidente el incremento significativo en el caso de las FARC. Finalmente, en mayo 24, el ministro de Defensa comunicó a la opinión pública que alias "Tirofijo", máximo comandante de las FARC, había muerto (aunque se desconocía la fecha de su muerte).

Gráfica 3: Número de deserciones individuales por grupo al margen de la ley, 2002-2008

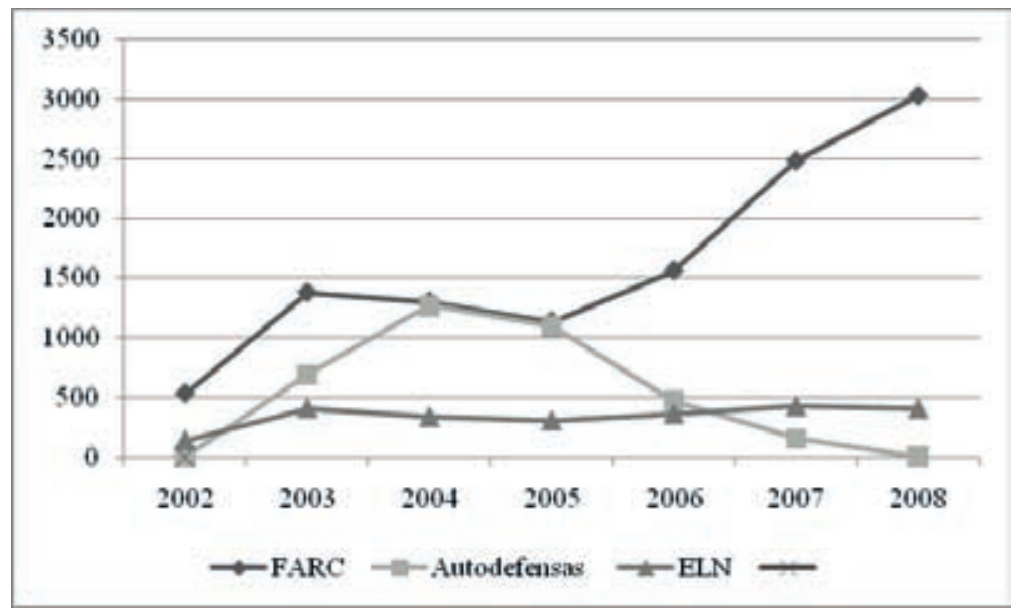

Fuente: Ministerio de Defensa.

Nunca antes en la lucha contrainsurgente había sido el gobierno tan exitoso militarmente como en el 2008. Además de los objetivos militares logrados para desarticular la

8 En los meses posteriores hubo algunos cuestionamientos sobre la utilización indebida del símbolo de la Cruz Roja y otras estrategias cuestionables dentro de la misión.

9 "Este año las Farc han enfrentado miles de casos como el de Karina. Según el Programa de Desmovilización del Ministerio de Defensa, desde el pasado primero de enero al 26 de octubre han desertado de las Farc 2.559 integrantes". Ver, Revista Semana (27 de octubre de 2008) "El descontrol de las FARC". [En línea] http:/ / www. semana.com/noticias-conflicto-armado/descontrol-farc/117129.aspx, [Consulta: 20-04-2009]. y también ver Fundación Ideas para la Paz (FIP). 2008. “Estadísticas sobre la Reinserción en Colombia”. [En línea] http:// www.ideaspaz.org/new_site/secciones/publicaciones/download_documentos/estadisticas_reinsercion_ colombia\%20(31\%20enero\%202008).pdf [Consulta: 20-04-2009]. 
organización, los índices de violencia, que venían cayendo, disminuyeron sustancialmente, dándole más energía a la política de no negociación con la guerrilla, y el proceso de paz con los paramilitares (Ver Anexo 1). Sin embargo, las organizaciones no gubernamentales y las decisiones de la Corte Constitucional presentaban resultados preocupantes en materia de derechos humanos y de respeto al proceso de reparación de víctimas y el desplazamiento. A pesar del pacto de desmovilización en el 2005, la persistencia de la presencia de más de 9.000 paramilitares formados en nuevos grupos en más de 25 departamentos del país, clara evidencia de las dificultades de la política de Verdad, Justicia y Reparación. ${ }^{10}$

Dadas las circunstancias, surgieron grandes cuestionamientos por parte de la oposición, los medios y organizaciones no gubernamentales acerca de la cercanía del gobierno a los líderes paramilitares y de su destreza para limitar su capacidad de acción, aún estando en la cárcel. ${ }^{11}$ Como respuesta a estas críticas, el 13 de mayo el presidente tomó la decisión de extraditar a los principales líderes paramilitares (sorpresiva para la opinión pública y para las víctimas). ${ }^{12}$ Las reacciones de apoyo de su coalición de gobierno contrastaron con los pronunciamientos hechos por las diferentes organizaciones representantes de las víctimas. Según éstas, se condicionaba las confesiones de los sindicados a su voluntad de cooperar judicialmente con Colombia, frenando el proceso de reparación. ${ }^{13}$ A estos cuestionamientos se unió la Corte Suprema de Justicia, la que procedió a solicitar de parte del gobierno una explicación de la repentina decisión. La respuesta del gobierno aludió a su autonomía para tomar este tipo de decisiones, estableciendo que la justicia norteamericana garantizaría el proceso de versiones libres que se venían realizando en Colombia, antes de que se diera la extradición. ${ }^{14}$

\section{b. Y los problemas: ¿Seguridad Democrática?}

Adicionalmente, durante el año se presentaron nuevos escándalos de abuso de poder por parte de diferentes organismos de seguridad del Estado. En el mes de octubre, el Departamento Administrativo de Seguridad (DAS) fue otra vez protagonista en las noticias por el descubrimiento de espionaje a miembros del Polo Democrático,

Comisión Colombiana de Juristas .2008. Informe para el examen periódico anual de Colombia. [En línea]: http:/ / www.coljuristas.org/archivos/infofinalepucol.pdf, [Consulta: 20-04-2009].

11 Ver por ejemplo Diario El Tiempo (21 de abril de 2008 ) "La violencia se ha recrudecido en sur de Bolívar y Magdalena medio rastro de ex 'para' recién fugado, tras amenazas de bandas". [En línea] http://www. eltiempo.com/archivo/documento/MAM-2905988 [Consulta: 20-04-2009].

12 En la alocución presidencial, el Jefe de Estado justificó la medida de esta manera: "Esta madrugada fue extraditado un grupo de ciudadanos porque algunos de ellos habían reincidido en el delito después de su sometimiento a la Ley de Justicia y Paz, otros no cooperaban debidamente con la justicia y todos incumplían con la reparación de las víctimas al ocultar bienes o demorar su entrega". Entre los paramilitares extraditados estaban Salvatore Mancuso, Rodrigo Tovar Pupo (Jorge 40), Diego Fernando Murillo ('Don Berna'), Hernán Giraldo, alias 'Pablo Sevillano' y Ramiro 'Cuco' Vanoy.

13 Ver, por ejemplo, Diario El Tiempo (14 de mayo de 2008) “¿Tras extradición de jefes paramilitares habrá verdad, justicia y reparación?". [En línea] http:/ /www.eltiempo.com/archivo/documento/CMS-4163130 [Consulta: 20-04-2009].

$14 \quad$ El proceso de versiones libres es parte del proceso al que se someten los líderes paramilitares en la Fiscalía para esclarecer los actos a las víctimas y sus familiares, establecido por la Ley de Justicia y Reparación. 
partido de oposición al Presidente Uribe. Este fue otro escándalo más en una cadena de atropellos que se desató desde el año 2005, cuando el entonces director del DAS y varios funcionarios de la institución fueron acusados y condenados por tener vínculos con los paramilitares. Estos vínculos se tradujeron, entre otras cosas, en compartir información reservada de miembros de la oposición, de líderes de base, sindicalistas, solicitada por los líderes paramilitares. Inclusive, se acusó al antiguo director del DAS -Jorge Noguera- de compartir información sobre procesos que pudiera ayudar a los líderes paramilitares en su negociación con la justicia.

Igualmente grave fue el escándalo de los homicidios sistemáticos cometidos presuntamente por agentes del Estado (o "falsos positivos", como se conoce estos casos en la prensa), que desató los más fuertes interrogantes a nivel nacional e internacional de organizaciones de derechos humanos acerca de los métodos de medición del éxito del Ejército, y del compromiso de las fuerzas militares con el Estado de Derecho. Se descubrió que en el afán de reportar bajas de parte de la guerrilla -y por ello recibir estímulos como días de vacaciones o puntos para su promoción interna-, miembros del ejército secuestraban jóvenes de barrios de las periferias urbanas, para luego asesinarlos y reportarlos como bajas guerrilleras. ${ }^{15}$ Con más de 324 casos reportados a finales del 2007, y más de 170 durante el 2008, se pusieron al descubierto prácticas sistemáticas de homicidios, así como la existencia de un siniestro mercado de víctimas que caían en manos de los traficantes con la falsa promesa de encontrar empleo como paramilitar o vigilante. Por cada uno de ellos, miembros del ejército pagaban entre 300 y 400 dólares. ${ }^{16}$ Aunque el Ministerio de Defensa afirma que los últimos casos fueron reportados en octubre $2008,{ }^{17}$ fuentes alternativas como el reporte especial del Centro de Investigación y Educación Popular (CINEP) sobre el tema, muestra un escenario muy distinto. ${ }^{18}$

15 Ver, por ejemplo, Diario El Tiempo (26 de enero de 2008) "Nos daban cinco días de descanso por cada muerto",. [En línea] http:/ / www.semana.com/noticias-nacion/daban-cinco-dias-descanso-cada-muerto/109046.aspx, [Consulta: 20-04-2009].

16 Ver: Diario El Tiempo (21 de marzo de 2008). “Entregué a más de 30 jóvenes para 'falsos positivos”. [En línea] http:/ / www.semana.com/noticias-nacion/entregue-30-jovenes-para-falsos-positivos/121974.aspx. [Consulta: 20-04-2009].

17 "Diario El Espectador (5 de marzo de 2009) "El problema de los falsos positivos ya fue resuelto: Mindefensa". [En línea] http:/ / www.elespectador.com/noticias/judicial/articulo124266-el-problema-de-los-falsos-positivosya-fue-resuelto-mindefensa [Consulta: 20-04-2009].

18 “Al finalizar el año 2008, el recuento de hechos de falsos positivos resulta preocupante, ya que se consolidó un importante incremento en el número de falsos positivos ocurridos en el año. Con relación a los casos que reportamos en septiembre pasado para el primer semestre del 2008 ( 26 casos y 54 víctimas), se ha producido un aumento del $34 \%$ en el semestre comprendido entre julio y diciembre de 2008, con un total de 35 casos de falsos positivos y un total de 69 víctimas. A ello se suman las actualizaciones que se hicieron a los datos del primer semestre en razón de las denuncias crecientes que se presentaron, entre ellas las de los jóvenes de Soacha. Por tanto, se agregan 34 casos más y 52 víctimas, para un gran total en todo el año 2008 de 95 casos y 175 víctimas. Ello implica un descenso en los 149 casos que se presentaron en el 2007, pero un incremento con respecto a los 68 casos registrados en el 2006". Centro de Investigación y Educación Popular (CINEP).2009. Informe Especial abril 2009 - Falsos Positivos: Balance del segundo semestre 2008. [En línea] :http:/ / www.cinep.org. co/sites/cinep.cinep.org.co/files/Informe\%20falsos \%20positivos\%202008-II\%20-\%20Abril\%202009\%20_FINAL_. pdf, [Consulta: 20-04-2009]. 
Tabla 1: Total número de víctimas de homicidios atribuibles a grupos paramilitares, al Ejército, fuerza pública y homicidios de responsabilidad compartida.

\begin{tabular}{lccccccccc}
\hline & \multicolumn{7}{c}{ Total de víctimas de homicidios atribuibles a grupos paramilitares, al } \\
& 2002 & 2003 & 2004 & 2005 & 2006 & 2007 & 2008 & Total \\
\hline & 56 & 93 & 134 & 120 & 172 & 298 & 165 & 1.038 \\
\hline Ejército & 29 & 23 & 46 & 39 & 25 & 78 & 35 & 275 \\
Fuerza pública & 960 & 1.422 & 660 & 357 & 140 & 267 & 372 & 4.178 \\
$\begin{array}{l}\text { Grupos paramilitares } \\
\text { Responsabilidad }\end{array}$ & 51 & 79 & 74 & 76 & 32 & 29 & 8 & 349 \\
$\begin{array}{l}\text { compartida } \\
\text { Otros }\end{array}$ & 0 & 0 & 0 & 0 & 0 & 1 & 0 & 1 \\
$\begin{array}{l}\text { Total ejecución } \\
\text { Extrajudiciales }\end{array}$ & 1.096 & 1.617 & 914 & 592 & 369 & 673 & 580 & 5.841 \\
\hline $\begin{array}{l}\text { Total casos reportados } \\
\text { como "falsos positivos" }\end{array}$ & 14 & 25 & 53 & 43 & 96 & 229 & 175 & 635 \\
\hline
\end{tabular}

Fuente: Informe Especial abril 2009 - Falsos Positivos: Balance del segundo semestre 2008, CINEP.

Como lo demuestran las cifras, el número de homicidios de parte de fuerzas paramilitares y fuerzas del Estado había disminuido sustancialmente desde el año 2003. Sin embargo, las cifras de los "falsos positivos" para el 2006, 2007 y 2008 incrementaron hasta sumar casi la tercera parte de las ejecuciones extrajudiciales. Esto podría sugerir que el desmantelamiento de los grupos paramilitares y sus conexiones con miembros del ejército tuvieron como consecuencia la búsqueda de nuevas formas de mostrar resultados, ya no por medio de los grupos paramilitares, sino por medio de acuerdos criminales con civiles. Aunque ya estaban en marcha algunas políticas para lidiar con este problema (las cifras de estos casos ya eran graves en los años anteriores), el Ministerio retiró del servicio a 20 oficiales (12 coroneles, 3 generales y 7 suboficiales). Actualmente, esta entidad adelanta investigaciones por medio de un Comité Interinstitucional de Seguimiento, creado para tal fin. Será importante ver las repercusiones de este fenómeno en el apoyo y financiación de Estados Unidos con la nueva administración en Washington.

\section{Contradicciones entre las mayorías y contrapesos del Presidente: El debate de la tercera reelección y las peleas con la Corte Suprema de Justicia}

Los años de la administración Uribe se han caracterizado por los más trascendentales cambios institucionales desde la Constitución de 1991. Sin lugar a dudas, la reforma al sistema electoral del 2003 y la reelección presidencial cambiaron el panorama político en el Congreso (ver Botero y Rodríguez Raga, 2006). Se robustecieron las estructuras partidarias, teniendo como resultado un sistema político de fuerzas predominantemente nacionales, donde hay una más clara división de fuerzas gubernamentales y oposición. Sin embargo, dada la alta popularidad del Presidente Uribe y su estilo confrontacional y mediático, el ejercicio de la oposición ha sido tímido y complicado. Y esto no 
necesariamente porque en lo institucional no se pueda ejercer la oposición a nivel de Congreso: simplemente, irse en contra de un presidente con el 75\% de aprobación es un negocio arriesgado, que no da muchos votos.

La siguiente gráfica muestra la evolución de la popularidad del Presidente Uribe en perspectiva comparada. En su segundo período, el promedio de favorabilidad fue del 73,5\%. En el 2008 éste fue del 78\%.

Gráfica 4: En general, ¿tiene usted una opinión favorable o desfavorable del Presidente?

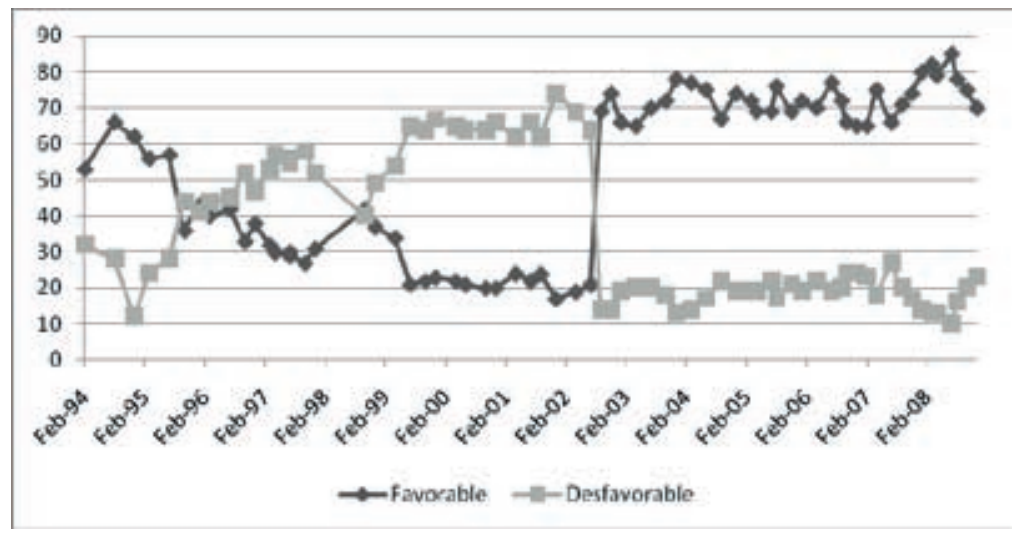

Fuente: Encuestas Gallup.

Sin embargo, ante los escándalos de corrupción y los falsos positivos, miembros de la oposición e incluso algunos de la coalición de gobierno decidieron irse en contra del presidente a pesar del rechazo de la opinión pública. ${ }^{19}$ En la coalición de gobierno, aunque hubo ciertos momentos de cuestionamientos de disidencias internas, en general la actitud de la mayoría de parlamentarios fue de total respaldo al presidente. ${ }^{20}$ Este respaldo irrestricto para muchos (que se interpretó más como fruto de la conveniencia que del apoyo a su plan de gobierno) se transformó en la propuesta de un tercer período para el Presidente Uribe. Para hacer esto posible, desde comienzos del año 2008 se propuso la presentación de un proyecto de acto legislativo que hiciera posible la segunda

19 Entre los enfrentamientos más sonados está el que el Presidente Uribe tuvo con el ex Presidente Gaviria, hoy Jefe único del Partido Liberal. Ver por ejemplo: El Tiempo (6 de septiembre de 2008) “¡Qué mamera!”,. [En línea] http:/ / www.semana.com/noticias-nacion/mamera/115253.aspx, [Consulta: 20-04-2009]

20 La Senadora Martha Lucía Ramírez, quien criticó fuertemente a Carlos García, Senador que fue sindicado por el caso de la parapolítica y Presidente del Partido de la U, renunció al Partido de la U finalmente en marzo del 2009. Gina Parody, Senadora del Partido de la U, decidió renunciar en las primeras semanas de enero por considerar que el proyecto de la segunda reelección rompía la tradición democrática del país y por otros proyectos de ley presentados por el presidente. Ver Diario El Tiempo (19 de enero de 2009). "Tras renunciar al Congreso, senadora Gina Parody dice que también se va de la 'U'”: [En línea] http:/ /www.eltiempo.com/ colombia/politica/senadora-gina-parody-anuncio-sorpresivamente-que-renunciara-al-congreso_4757017-1, [Consulta: 20-04-2009]. 
reelección del presidente, mientras se recogían las firmas para presentar un proyecto de referendo al Congreso de la República. Aunque el acto legislativo podría ser una vía más expedita, el temor de los congresistas de no tener mayorías suficientes a raíz de las investigaciones de parapolítica, los llevó a comenzar el trámite de recoger firmas para posteriormente presentar el proyecto de referendo al Congreso, el cual sólo requería de mayoría simple para ser aprobado.

Ante esta posibilidad, los partidos políticos en la oposición y el Partido Cambio Radical, miembro de la coalición de gobierno, pidieron al presidente claridad acerca de sus preferencias sobre esta propuesta de los miembros de su coalición. Sin embargo, el silencio del presidente y su ambigüedad ante la pregunta sobre si efectivamente estaría interesado en un tercer periodo, fue constante durante todo el año. A finales del 2007 el presidente respondió que únicamente se lanzaría a un tercer periodo en caso de una "hecatombe". En otras ocasiones, el presidente se pronunció a favor de la reelección de la política de Seguridad Democrática, sugiriendo que lo importante no era que él continuara, sino que hubiera continuidad. La ambigüedad de parte del presidente, aunque cuestionable en otras dimensiones, ha garantizado la continuidad y estabilidad de su coalición, en la cual se encuentran los posibles candidatos presidenciales con mayor probabilidad de ganar.

Para Uribe la incertidumbre evitó que los líderes de los movimientos de la coalición intentaran "diferenciarse" con miras a la contienda electoral. Por esto, se observaron altos niveles de precaución de los líderes que se alejaron de la coalición de gobierno. ${ }^{21}$ Tal fue el caso del líder del Partido Cambio Radical, senador Germán Vargas Lleras, quien decidió renunciar a su curul en junio, con la excusa de darle vía libre a la reforma política en la Comisión Primera, a pesar de la negativa dada al proyecto desde la Casa de Nariño. La razón, obvia para muchos analistas, era que esta era la forma más fácil de darle comienzo a su campaña presidencial..$^{22}$ Para los legisladores, promover un tercer periodo ofrecía (y continúa ofreciendo) grandes ventajas. Muchos de los legisladores investigados por escándalos de parapolítica eran parte de la coalición de gobierno. La sombra del presidente en elecciones les permitiría protegerse de los escándalos, justificar su negativa a la aprobación de proyectos de reforma política y otros que pretendían dar una solución a la crisis de legitimidad. ${ }^{23}$

Y si bien el Presidente Uribe no tuvo grandes confrontaciones en el Congreso, sus interacciones con otras ramas del poder fueron altamente combativas, especialmente en relación con el tema de las investigaciones de congresistas por parapolítica. Uno de sus conflictos más publicitado ocurrió con el presidente de la Corte Suprema de Justicia, quien en una entrevista acusó al Presidente Uribe de querer intervenir en el proceso de investigación por parapolítica del senador Mario Uribe, familiar del presidente.

21 En este periodo no se vieron muchos cambios de gabinete comparado con el periodo anterior, cosa que cambia en el 2009 por ser un periodo preelectoral y por las incompatibilidades que establece la ley para participar como candidato en las elecciones. Ver Anexo 2.

22 Ver, por ejemplo, Diario El Tiempo (3 de junio de 2008) "Reelección del presidente Uribe sin los votos de Cambio Radical, no pasa", dice Elisabeth Ungar". [En línea] http:/ /www.eltiempo.com/archivo/documento/CMS4232455 [Consulta: 20-04-2009].

23 Uno de los proyectos más discutidos fue el de la "Silla vacía". 
La reacción del presidente fue la de demandar al presidente de la Corte por injuria y calumnia, frente a la Comisión de Acusaciones de la Cámara de Representantes. ${ }^{24}$ Las demás investigaciones sobre la parapolítica continuaron durante todo el año y dieron pie a nuevos enfrentamientos con la Corte Suprema. En varias ocasiones, miembros del gabinete acusaron a la Corte de no ser imparcial en los casos de los congresistas pertenecientes a la coalición de gobierno, afirmando que las decisiones para condenar a estos legisladores eran basadas en "inferencias" y no en acervos probatorios de acuerdo a la ley. Y quienes fueron condenados acusaron a algunos magistrados de la Corte por manipulación y chantaje de testigos. ${ }^{25}$ Dado este diagnóstico, muchos congresistas decidieron renunciar a su investidura por considerar que la Fiscalía sería un ente más imparcial para estudiar sus casos, ofreciendo una segunda instancia con la que no se contaba en el caso de ser juzgado por la Corte Suprema de Justicia (Ver Anexo 2 para ver los casos acumulados de congresistas vinculados con la parapolítica). ${ }^{26}$

El otro caso por el cual hubo enfrentamientos entre la rama ejecutiva y la Corte Suprema fue el de la "Yidis-política". La ex representante a la Cámara, Yidis Medina, quien ya había sido investigada en el 2004 por su cambio de voto en el acto legislativo de la reelección por la Procuraduría (sin ningún resultado), confesó ante las cámaras de un noticiero en el mes de abril haber cambiado su voto por cuotas burocráticas. ${ }^{27}$ Igualmente, en su entrevista estableció que lo prometido por el Ejecutivo no se había cumplido. Dada su autoincriminación, la Corte ordenó su captura, siendo condenada por la Corte Suprema a ocho años de cárcel por el delito de cohecho. ${ }^{28}$ Como su confesión vinculaba al entonces ministro del Interior Sabas Pretelt de la Vega, al ministro de Protección Social, Diego Palacios y al Secretario General del Palacio, Alberto Velásquez, de participar en este delito, la Corte decidió abrir nuevas investigaciones a estos altos funcionarios del gobierno. El presidente, en respuesta al cuestionamiento acerca de la validez del acto legislativo de la reelección, propuso la realización de un referendo para que fueran los votantes quienes dijeran si su segundo mandato era legítimo. Finalmente, esta idea fue abandonada gracias a la intervención del ministro del Interior, Fabio Valencia Cossio, quien entró a ocupar el puesto de Carlos Holguín Sardi, antiguo senador y Jefe del Partido Conservador quien renunció. A pesar de las investigaciones y activo rol de la Corte, finalmente las investigaciones a los miembros del gabinete no terminaron en

24 Ver Revista Semana (3 de mayo de 2008) “Pelea de Barrio". [En línea] http://www.semana.com/noticiasnacion/pelea-barrio/111515.aspx [Consulta: 20-04-2009].

25 Ver, por ejemplo, Diario El Tiempo (25 de mayo de 2008). “Los fallos de la Corte son políticos y van contra del Presidente Uribe. El Senador Mauricio Pimiento". [En línea]: http:/ /www.eltiempo.com/archivo/documento/ MAM-2949565 [Consulta: 20-04-2009].

26 Esta reforma se hundió a mediados de junio, porque se requería una mayoría calificada que no se consiguió, dada la declaración de impedimentos de varios senadores por investigaciones por vínculos con los paramilitares.

27 Cuotas burocráticas es un término que se usa comúnmente para referirse a un número de puestos que ofrece un funcionario del gobierno a un legislador en la burocracia, que son generalmente de libre nombramiento y remoción.

28 Ver Diario El Tiempo (15 de mayo de 2008) “El Procurador reabre caso de Yidis Medina". [En línea] http:// www.eltiempo.com/archivo/documento/MAM-2935808, [Consulta: 20-04-2009] ver Diario El Tiempo (27 de junio del 2008) “Condena A Yidis: Corte Suprema Cuestiona Aprobación de Reelección”. [En línea]: http: / / www.eltiempo.com/archivo/documento/MAM-2991839 [Consulta: 20-04-2009]. 
capturas. A tal punto llegaron los enfrentamientos, que en agosto del 2008 la Corte llegó a emitir un comunicado en el cual se afirmó que el alto gobierno, encabezado por el Presidente de la República, habría emprendido una campaña de desprestigio a la Corte que violentaba el Estado de Derecho y que era necesario reportar estos actos a organismos internacionales.

Como es aparente, estos enfrentamientos -sumados a los cuestionamientos que se vienen dando sobre la independencia de los organismos de control desde la aprobación de la reelección-, son algo preocupantes en términos de la estabilidad institucional y la existencia de efectivos balances y contrapesos (Ver Botero, 2008). El ataque a las Cortes por parte del Ejecutivo, así como sus nombramientos en la Corte Constitucional y en el Banco de la República, cuestiona su potencial como instituciones que puedan ejercer su labor de contrapeso a la figura presidencial. Esta preocupación se incrementa por la incertidumbre por el proyecto de referendo que actualmente hace curso en el Congreso.

\section{Coyuntura Internacional}

En materia de relaciones internacionales, el 2008 tuvo un comienzo representativo de la tensión del conflicto colombiano entre el cumplimiento de las normas internacionales y el avance en la guerra contra las FARC. Igualmente, comparado con el año anterior, el primer semestre vio un cambio cualitativo en la posición de la comunidad internacional al redireccionar su presión y crítica a las FARC y al gobierno venezolano. Sin embargo, el cambio de administración en Estados Unidos y los escándalos de los homicidios cometidos por agentes del Estado cambiaron de nuevo la tendencia al cuestionarse de nuevo el compromiso de la administración Uribe con el Estado de Derecho.

Al final del 2007 la insistencia internacional por el intercambio humanitario se incrementó en gran medida como reacción a la precaria situación de salud de algunos de los secuestrados revelada por las pruebas de supervivencia. Dada la posición de Uribe frente al intercambio humanitario, quienes estaban interesados en que éste se diera creían que sólo por medio del Presidente Chávez y de la senadora Piedad Córdoba era posible rescatar a los secuestrados con vida. En diciembre, a raíz del anuncio de la entrega de algunos de los secuestrados (Consuelo González, Clara Rojas y su hijo Emmanuel), la presencia de la Misión Humanitaria Internacional en el territorio nacional en la zona de encuentro aumentó el ambiente de crítica al gobierno colombiano (Ver Botero, 2008). ${ }^{29}$ La tensión aumentaba en la medida que las FARC culpaban la demora de la entrega al gobierno por no ofrecer las suficientes garantías, mientras que pacientemente se esperaba por las coordenadas de los secuestrados que se habrían prometido liberar. La situación dio un giro de 180 grados a favor del gobierno, cuando el presidente comunicó a la comunidad internacional que Emmanuel, el hijo de Clara Rojas, no estaba en manos de las FARC. La historia de Emmanuel era desgarradora: nacido durante el cautiverio, había sido separado de su madre y puesto en las manos de miembros de las FARC. El niño

29 La misión estaba compuesta por representantes del gobierno del Ecuador, Brasil, Argentina, Francia, Cuba, Bolivia, Colombia y Suiza. 
habría sido enviado a un hogar del bienestar familiar (parte del Instituto Colombiano del Bienestar Familiar) por un funcionario, quien recibió al niño en un centro de atención en un muy lamentable estado de salud.

Aunque continuó su labor como gestor en las liberaciones, su ataque mediático disminuyó considerablemente. Finalmente, la entrega de los secuestrados se materializó en enero 10. En una alocución en días posteriores a la liberación, el Presidente Chávez solicitó a la comunidad internacional el retirar a las FARC de la lista de terroristas, lo cual fue abiertamente rechazado por Colombia y la comunidad internacional. Sin embargo, su labor de intermediación continuó consolidándose al darse la liberación unilateral de seis secuestrados más el 27 de febrero. A pesar de los gestos de las FARC, su propuesta de creación de una zona desmilitarizada para el intercambio fue inmediatamente rechazada.

Las tensiones con Venezuela se hicieron evidentes en la crisis con Ecuador, por la operación realizada el primero de marzo en territorio ecuatoriano, en la cual resultó muerto alias "Raúl Reyes", miembro del secretariado y segundo al mando de las FARC. El Presidente Chávez, junto con los presidentes Rafael Correa de Ecuador y Daniel Ortega de Nicaragua, condenaron el operativo colombiano como una clara violación de la soberanía y rompieron relaciones diplomáticas con Colombia. Adicionalmente, el Presidente Chávez movilizó tropas a la frontera colombo-venezolana. A su turno, el Presidente Uribe respondió amenazando al presidente venezolano de denunciarlo ante la Corte Penal Internacional por la financiación de terroristas. ${ }^{30}$

La crisis diplomática tuvo resolución en la Cumbre de Río, en República Dominicana, en donde Colombia pidió perdón a Ecuador por la intromisión de su territorio, y donde respondiendo a la solicitud de los demás líderes presentes, los presidentes de las cuatro naciones prometieron distender las relaciones y dejar el evento en el pasado. ${ }^{31} \mathrm{~A}$ pesar de esto, en los meses subsiguientes a la crisis diplomática se establecieron nuevas restricciones para los colombianos en la frontera ecuatoriana. Aunque se dieron algunos esfuerzos internacionales por mediar y normalizar las relaciones diplomáticas entre los dos países (OEA, el Centro Carter y el Grupo Binacional de Diálogo), el Presidente Correa se rehusó a restablecer relaciones con Colombia. El entrante Canciller, Jaime Bermúdez, en una actitud poco negociadora, afirmó que Colombia reanudaría las relaciones con Ecuador siempre y cuando Ecuador cumpliera unos mínimos requisitos, en los que se incluía su colaboración en la frontera en la lucha contra las FARC. ${ }^{32}$ La respuesta negativa

30 Durante la operación fueron incautados varios discos duros y computadores pertenecientes a Raúl Reyes, en los cuales se encontró evidencia sobre comunicaciones de los líderes de las FARC con varios líderes de la región. La evidencia fue enviada a la INTERPOL para garantizar que el gobierno colombiano no la estuviera manipulando. La INTERPOL se pronunció unos meses después aseverando que los computadores y sus documentos no habían sido alterados.

31 Ver Diario El Tiempo (7 de marzo de 2008) “Gestos y anuncios en la Cumbre de Río que permitieron poner fin a la crisis". [En línea] http://www.eltiempo.com/archivo/documento/CMS-3992208 [Consulta: 20-04-2009].

32 Ver: Diario El Tiempo (26 de junio del 2008) “'Mientras Uribe sea el Presidente no Habrá Relaciones', dice Rafael Correa". [En línea] http://www.eltiempo.com/archivo/documento/MAM-2990250 [Consulta: 20-04-2009]. 
de Correa fue aún más enfática, estableciendo que mientras el Presidente de Colombia fuera Álvaro Uribe, Ecuador no cambiaría su posición.

El otro tema que dominó la agenda de Colombia fue la negociación y firma de tratados de libre comercio (Unión Europea EFTA), los tratados bilaterales de inversión con Suiza, Perú, China, Bélgica y Luxemburgo y los tratados de doble tributación. En el tema del tratado de libre comercio con Estados Unidos, los perseverantes esfuerzos del gobierno colombiano y su labor de lobby en el Congreso no dieron los resultados esperados, al no lograr concretar una posición en la agenda que le permita su aprobación.

Finalmente, el tema que queda en la mesa para el 2009 son las reacciones de los organismos internacionales ante los "falsos positivos". Después de un año con relativa calma y reconocimiento internacional por el esfuerzo y efectividad de las fuerzas militares, estos hechos - por su gravedad-pueden tener repercusiones muy negativas en la continuidad de la financiación.

\section{Coyuntura Económica}

Después de una tasa de crecimiento sobresaliente del Producto Interno Bruto, que alcanzó el 7,5\% en 2007, durante el año 2008 la economía del país empezó a mostrar una clara desaceleración desde el primer trimestre y decreció en el cuarto trimestre, mostrando una tasa de crecimiento anual del $2,5 \%$, por debajo de las perspectivas tanto del Gobierno como de la mayoría de analistas macroeconómicos del país. Si bien una parte importante de la menor dinámica productiva de la economía colombiana en 2008 se originó en factores domésticos, la profundización de la crisis financiera de Estados Unidos y su posterior efecto sobre el comercio mundial serán fuente de la desaceleración en 2009. En efecto, el Fondo Monetario Internacional estima que la economía mundial se contraerá 1,3\% para el 2009, la peor recesión desde la Segunda Guerra Mundial, y que sólo crecerá 1,9\% en 2010. Para Colombia, el FMI estima un crecimiento de $0 \%$ en 2009, con una leve recuperación del 1,3\% en $2010 .{ }^{33}$ Estas proyecciones están en el rango de los estimativos de Fedesarrollo y un poco por debajo de los cálculos del Gobierno. ${ }^{34}$

Aunque en 2008 se observó una desaceleración generalizada, los sectores que más contribuyeron a los negativos resultados fueron la industria manufacturera, la construcción y el comercio. Aunque el crecimiento de la minería fue superior durante 2008, la contribución de los servicios financieros al crecimiento del PIB fue la más importante. Por el lado de la demanda se observó una desaceleración del consumo final, la inversión y las exportaciones. El peor desempeño de la actividad productiva y la demanda se vio reflejada en los indicadores de empleo y el balance fiscal y externo. En efecto, la tasa de desempleo alcanzó el 10,5\% en el cuarto trimestre de 2008, 0,67 puntos porcentuales superior a la observada el mismo trimestre de 2007. 
Tabla 2: Crecimiento del PIB, Índice de Precios al Consumidor y Balance en cuenta corriente para países seleccionados.

\begin{tabular}{|c|c|c|c|c|c|c|c|c|c|c|c|c|}
\hline & \multicolumn{4}{|c|}{ Crecimiento del PIB } & \multicolumn{4}{|c|}{$\begin{array}{l}\text { Índice de Precios } \\
\text { al Cosumidor }\end{array}$} & \multicolumn{4}{|c|}{$\begin{array}{l}\text { Balance en cuenta } \\
\text { corriente }\end{array}$} \\
\hline & 2007 & 2008 & 2009 & 2010 & 2007 & 2008 & 2009 & 2010 & 2007 & 2008 & 2009 & 2010 \\
\hline ccidental & 5,7 & 4,2 & $-1,5$ & 1,6 & 5,4 & 7,9 & 6,6 & 6,2 & 0,4 & $-0,7$ & $-2,2$ & $-1,6$ \\
\hline udamérica y México & 5,7 & 4,2 & $-1,6$ & 1,6 & 5,3 & 7,7 & 6,7 & 6,3 & 0,7 & $-0,3$ & $-1,9$ & $-1,3$ \\
\hline Argentina & 8,7 & 7,0 & $-1,5$ & 0,7 & 8,8 & 8,6 & 6,7 & 7,3 & 1,6 & 1,4 & 1,0 & 1,8 \\
\hline Brasil & 5,7 & 5,1 & $-1,3$ & 2,2 & 3,6 & 5,7 & 4,8 & 4,0 & 0,1 & $-1,8$ & $-1,8$ & $-1,8$ \\
\hline hile & 4,7 & & 0,1 & 3,0 & 4,4 & 8,7 & 2,9 & 3,5 & 4,4 & $-2,0$ & $-4,8$ & $-5,0$ \\
\hline olombia & 7,5 & 2,5 & 0,0 & 1,3 & 5,5 & 7,0 & 5,4 & 4,0 & $-2,8$ & $-2,8$ & $-3,9$ & $-3,3$ \\
\hline Ecuador & 2,5 & 5,3 & $-2,0$ & 1,0 & 2,3 & 8,4 & 4,0 & 3,0 & 2,3 & 2,4 & $-3,5$ & $-2,3$ \\
\hline México & 3,3 & 1,3 & $-3,7$ & 1,0 & 4,0 & 5,1 & 4,8 & 3,4 & $-0,8$ & $-1,4$ & $-2,5$ & $-2,2$ \\
\hline Perú & 8,9 & 9,8 & 3,5 & 4,5 & 1,8 & 5,8 & 4,1 & 2,5 & 1,4 & $-3,3$ & $-3,3$ & $-3,2$ \\
\hline Uruguay & 7,6 & 8,9 & 1,3 & 2,0 & 8,1 & 7,9 & 7,0 & 6,7 & $-0,8$ & $-3,6$ & $-1,7$ & $-2,4$ \\
\hline Venezuela & 8,4 & 4,8 & $-2,2$ & $-0,5$ & 18,7 & 30,4 & 36,4 & 43,5 & 8,8 & 12,3 & $-0,4$ & 4,1 \\
\hline América Central & 6,9 & 4,3 & 1,1 & 1,8 & 6,8 & 11,2 & 5,9 & 5,5 & $-7,0$ & $-9,2$ & $-6,1$ & $-7,1$ \\
\hline El Caribe & 5,8 & 3,0 & $-0,2$ & 1,5 & 6,7 & 11,9 & 4,0 & 5,8 & $-1,5$ & $-2,8$ & $-5,1$ & $-4,1$ \\
\hline
\end{tabular}

Fuente: FMI, World Economic Outlook (WEO): Crisis and Recovery. Abril 2009.

En el frente fiscal, el Ministro de Hacienda siempre ha sostenido que el país y en particular las finanzas públicas están "blindadas" para enfrentar la desaceleración de la economía. El balance fiscal del Sector Público Consolidado fue de $-0,1 \%$ del PIB ${ }^{35}$. Para 2009 se prevé un incremento de este déficit como consecuencia de menores ingresos tributarios y los mayores gastos del gobierno para enfrentar la desaceleración de la actividad productiva. En el frente externo, entre 2003-2008 el balance promedio en cuenta corriente de Colombia fue deficitario en 1,8\% del PIB. Para 2009 se estima que el déficit en cuenta corriente puede llegar al $4 \%$ del PIB y aunque no se prevén problemas de financiación, el gobierno decidió acceder a una línea de crédito contingente del Fondo Monetario Internacional (FMI), que pone a disposición del Banco de la República más de US\$10 mil millones para garantizar la estabilidad cambiaria del país en caso de que se presenten problemas de financiación.

En resumen, los canales de transmisión de la crisis global tales como menor demanda por las exportaciones del país, una caída en las remesas de los colombianos residentes en el exterior y una menor Inversión Extranjera Directa (IED) sólo se empezarán a sentir plenamente en 2009. En efecto, la IED durante 2008 registró US\$ 10.564 millones, lo cual equivale a un incremento de US\$1.524 millones con respecto a 2007, una cifra récord.

35 Este resultado fiscal se explica por un superávit del Sector Público no Financiero (SPNF) de 0,1\% del PIB, un superávit del balance cuasifiscal del Banco de la República de 0,3\% del PIB, un superávit de 0,1\% de Fogafin, costos de la reestructuración financiera por $0,3 \%$ del PIB y una discrepancia estadística de $0,3 \%$ del PIB. 
Uno de los frentes en los cuales hubo mayor presión durante 2008 fue la inflación. El Índice de Precios al Consumidor aumentó 7,78\% en 2008 con respecto al año anterior. El comportamiento de los precios obligó al Banco de la República a incrementar su tasa de intervención durante el primer semestre y al final del año la caída de los precios internacionales de los productos básicos, la menor demanda interna y la caída de la confianza de los consumidores y los empresarios registrada en las encuestas de Fedesarrollo, redujeron la presión inflacionaria. Ante esta evidencia, el Banco de la República, en la reunión del 19 de diciembre de 2008, redujo la tasa de interés de intervención en 50 puntos básicos.

En conclusión, los efectos nocivos de la desaceleración mundial se empezaron a sentir en Colombia a finales de 2008 y se espera una profundización en 2009. Estos resultados negativos de la actividad productiva van a generar retos de política pública para los gobiernos nacionales y locales. Se espera que una agresiva inversión pública en infraestructura y un incremento en los programas sociales ayuden a reducir los impactos negativos del menor crecimiento esperado a pesar de la inminente recesión. ${ }^{36}$

\section{a. Estado de emergencia económica y el escándalo de las pirámides}

Además de la desaceleración económica, en los últimos meses del año, el gobierno tuvo que hacer frente a uno de los fenómenos más complejos de masiva captación ilegal de dinero. $\mathrm{Al} \mathrm{mismo} \mathrm{tiempo} \mathrm{que} \mathrm{algunos} \mathrm{de} \mathrm{los} \mathrm{Fondos} \mathrm{más} \mathrm{prestigiosos} \mathrm{de} \mathrm{Wall} \mathrm{Street}$ caían -revelando ser pirámides y no inversiones productivas-, en Colombia firmas que tenían el mismo modus operandi comenzaron a cerrar sus oficinas, fugándose con el capital de poblaciones enteras donde estos esquemas sustituyen al sector financiero, dejando ahorradores de ciudades enteras sin su capital. ${ }^{37}$ En los departamentos de Nariño y Putumayo, por ejemplo, como consecuencias de los cierres se generaron disturbios de orden público y saqueos, lo que obligó a decretar toques de queda en las dos capitales y en varios municipios. La crisis fue tal que obligó al Gobierno Nacional a tomar medidas más drásticas con respecto a este tipo de negocio a pesar de haber tolerado su existencia por años.

Una de las firmas intervenidas fue la comercializadora DMG, que en pocos años se había convertido en un emporio difícil de ignorar, contando con más de 300.000 afiliados, y con presencia nacional. ${ }^{38} \mathrm{El} 15$ de noviembre, el presidente, haciendo uso de sus poderes

36 Para ver la prioridad de inversiones establecidas para el año 2009, ver el Documento CONPES 3532, Plan Operativo Nacional de Inversiones Vigencia 2009, julio 14 del 2008., Ministerio de Hacienda y Crédito Público.

37 En las noticias se decía que el desfalco de la pirámide “Dinero Rápido, Fácil y Efectivo” y sus satélites podrían sumar los 2 billones de pesos. Diario El Tiempo (14 de noviembre del 2008) Ver, por ejemplo, "La historia de DRFE, la pirámide que puso a temblar a 11 departamentos". [En línea] http:/ / www.eltiempo.com/archivo/ documento/CMS-4664899 [Consulta: 20-04-2009].

38 “El gobierno sospecha que detrás de las 'pirámides' se esconden mecanismos de lavado de dinero del narcotráfico. Por ello, pidió a la Fiscalía investigar a 1.302 entidades que realizaron transacciones sospechosas y pidió colaboración a la DEA, agencia antidrogas de Estados Unidos". Ver Diario El Tiempo (13 de noviembre del 2008). [En línea] http:/ /www.eltiempo.com/archivo/documento/CMS-4663770 [Consulta: 20-04-2009]. 
extraordinarios, declaró el estado de emergencia económica y social, con los cuales logró expedir decretos legislativos que le permitieron intervenir las sedes de DMG y de otros cientos de pirámides (o ponzi scheme) que venían siendo investigadas por la Fiscalía. ${ }^{39}$ La acción del gobierno generó gran oposición en los afectados, muchos de los cuales hicieron manifestaciones públicas a favor de David Murcia Guzmán (DMG), presidente de la comercializadora. Este y sus socios más cercanos se encuentran detenidos por la Fiscalía, acusados por captación masiva ilegal de dinero y lavado de activos. Los escándalos de corrupción y financiación de campañas políticas de estos grupos ya son investigados y se espera para el 2009 tener resultados. Igualmente, varios son los cuestionamientos al gobierno y a los entes de control por su lenta reacción a este fenómeno. Muy seguramente, esta falla será explotada por la oposición en las campañas presidenciales para el 2010.

\section{Actividad Legislativa ${ }^{40}$}

Aunque el periodo se caracterizó por una relativa estabilidad de la mayoría del presidente en el Congreso, el 2008 no sobresale en la administración Uribe por tener una agenda muy dinámica, a pesar del número de proyectos que fueron presentados en la legislatura (Congreso Visible, 2009). Esto se atribuye en parte a los escándalos de la parapolítica. Como se evidencia en el Anexo 2, las investigaciones de parapolítica a fines del año involucraban a más de 73 parlamentarios. Según el informe de Congreso Visible, para el final de la legislatura que terminaba en junio del 2008, 52 parlamentarios habían cedido su curul, de los cuales 31debieron ser reemplazados por acusaciones penales.

En algunos proyectos de trascendencia, muchos de los parlamentarios debieron declararse impedidos por las investigaciones en curso, lo que dificultó la aprobación de proyectos que ya iban adelantados en su proceso legislativo, como lo fue la reforma política, mejor conocida como la "Silla Vacía", que naufragó en su quinto debate. ${ }^{41} \mathrm{El}$ acto legislativo, además de establecer nuevas sanciones para los legisladores que se les comprobasen acuerdos con grupos ilegales, tenía como objetivo fundamental el impedir los reemplazos para los casos en los cuales se perdiera la curul en caso de encontrar al parlamentario culpable por alianzas con grupos ilegales. ${ }^{42}$ A pesar de que el proyecto inicial fue promovido por el gobierno, la inclusión en el artículo de la "silla vacía" fue lo que le dio dinamismo en el Congreso, para conseguir el apoyo de sectores de la oposición. Sin embargo, a medida que aumentaba el número de legisladores involucrados,

39 Ver en El Tiempo, “Gobierno intervino al grupo DMG”. (15 de noviembre del 2008).[En línea]: http:/ /www. eltiempo.com/archivo/documento/CMS-4668512 [Consulta: 20-04-2009].

40 Congreso Visible. 2008. Boletín en Línea N $\mathrm{N}^{\circ}$ 7: Balance Legislativo: Legislatura 2008-2009 periodo I. [En línea] http:/ / cvisible.uniandes.edu.co/var/rw/CMS/novedadesBibliografica/Boletin\%20en\%20Linea/ NUEVO!\%20Boletin $\% 20$ en $\% 201$ inea $\% 20$ No $\% 207 /$ Boletin $\% 20$ en $\% 201$ inea $\% 20 \mathrm{No} \% 207$.pdf [Consulta: 20-04-2009].

41 Se le llamó el proyecto de la "silla vacía", porque se propuso que los partidos perdieran su curul en caso de comprobar que el congresista tuviera relaciones con grupos armados.

42 La reforma también establecía la devolución de dineros públicos en caso de ser hallado culpable, así como la pérdida de personería jurídica a aquellos partidos que tuvieran más del 50\% de sus miembros involucrados en negociaciones con grupos ilegales. 
la obstaculización de su proceso por parte del gobierno y su coalición fue evidente, especialmente cuando se propuso que la sola apertura de investigación del legislador justificaba la pérdida de la curul para el Partido. Igualmente, sectores minoritarios se opusieron vehementemente a la reforma por considerar que el incrementar el umbral del 2 al 5\% para la asignación de curules era un directo atentado a su existencia. ${ }^{43} \mathrm{El}$ argumento del aumento del umbral se utilizó argumentando que precisamente los pequeños partidos de corte regional representaban la mayor amenaza para ser cooptados por grupos ilegales. Sin embargo, algunos parlamentarios, entre los cuales estaba la Senadora uribista Gina Parody, consideraban este argumento carente de validez, en parte porque los grandes partidos eran los que tenían mayor número de investigados. Aunque actualmente una nueva reforma política sigue su curso en el Congreso (al escribir este artículo) que intenta dar una solución institucional a la crisis que se ha presentado, éste establece que las sanciones regirán sólo a partir del 2009. Por estas razones, y por la época de comienzo del ciclo preelectoral, es muy probable que este proyecto de acto legislativo tenga la misma suerte de su predecesor.

Otro de los proyectos que tuvo un trámite similar a la reforma política fue la ley de reparación de víctimas. Este proyecto de iniciativa del Partido Liberal, que comenzó con un gran apoyo por parte las diversas fuerzas del Congreso y de las organizaciones representantes de las víctimas del desplazamiento, tuvo una difícil iniciación por objeciones del entonces saliente Ministro del Interior, Carlos Holguín Sardi, quien cuestionó la viabilidad de la propuesta y la capacidad del Estado de ejercer las obligaciones plasmadas en texto inicial. El Ministro Valencia Cossio, quien ocupó el Ministerio en Junio, reiteró la preocupación del gobierno por tener un proyecto más equilibrado que permitiera resarcir a las víctimas sujeto a los límites presupuestales. Aunque el proyecto fue aprobado en primer debate, aún en contra de las objeciones del Ejecutivo, los debates subsiguientes vieron su texto original altamente enmendado. Entre otras reformas, se estableció en el nuevo proyecto que el Estado resarciría a las víctimas por solidaridad y no por responsabilidad, que para ser reconocidos como víctimas, los interesados deberían tener el reconocimiento de una sentencia judicial y, finalmente, que en la definición de víctimas únicamente incluiría aquellos que hubieren sido atacados por fuerzas ilegales, sin incluir fuerzas estatales. Dadas estas variaciones y otras de carácter logístico (límite de tiempo en el cual pueden declararse víctimas, y tope de la compensación), los autores del proyecto decidieron a finales de noviembre retirarlo de la agenda y reanudar su trámite en la siguiente legislatura.

Con la entrada del nuevo Ministro, Fabio Valencia, el Ejecutivo introdujo un proyecto de reforma a la justicia que pretendía ofrecer soluciones a los llamados "choques de trenes" entre el Ejecutivo y la rama judicial. La reforma propuesta incluía, entre otros puntos, resolver el problema de la "segunda instancia" para el caso de juzgamiento de

43 Revista Semana (17 de abril del 2008). “Al país no le conviene regresar al Frente Nacional”: David Luna. [En línea] http://www.semana.com/noticias-on-line/pais-no-conviene-regresar-frente-nacional-david-luna/111059. aspx [Consulta: 20-04-2009]. 
congresistas. ${ }^{44} \mathrm{Y}$ a pesar de ser el proyecto bandera del ministro, era de conocimiento público que tendría grandes retos en su consideración. En el Congreso, muchos de los congresistas anticipaban declararse impedidos en la votación por estar en esos momentos siendo investigados, a pesar de la insistencia del ministro por considerar que esto no era necesario. Y, por otro lado, las altas Cortes consideraron nocivo discutir el cambio de reglas que estaban en plena vigencia por las investigaciones de parapolítica. Los magistrados se pronunciaron igualmente frente al proyecto considerando que las razones de la presentación eran insuficientes. El proyecto, que fue presentado al comienzo de la segunda legislatura de 2008, se retiró en octubre al no encontrar consenso al interior de la coalición ni apoyo de la rama judicial. ${ }^{45}$ Con éste, han sido cuatro los proyectos de reforma a la justicia que ha presentado y retirado el gobierno desde el comienzo del primer período de Uribe.

Es así como la agenda del Congreso no avanza en materia sustancial durante el año en la aprobación de proyectos, lo cual refleja de alguna manera la falta de consensos acerca de estas materias y los límites de la mayoría gobiernista. Sin duda, el proyecto más controversial que entró en la legislatura fue el referendo que permitiría la reelección del presidente por una segunda vez. El debate acerca del tercer periodo se intensificó en noviembre, puesto que en el proyecto de reforma política se incluyó un artículo que proponía que Uribe podría lanzarse en el 2014, y no en el 2010 como lo haría el referendo. Finalmente el artículo fue negado. El proyecto de referendo comenzó su tránsito legislativo, no sin ser altamente cuestionado por la oposición, la cual ha sido muy diligente en encontrarle inconsistencias a la financiación de la recolección de firmas, incluyendo violaciones al límite de financiación total y per diem que está permitido. ${ }^{46}$

Sin duda, este es el proyecto de mayor trascendencia durante el comienzo del 2009. $\mathrm{Si}$ el referendo es aprobado por las mayorías uribistas en el Congreso, la ley deberá ir posteriormente a la Corte Constitucional, la cual determinará su constitucionalidad. La Corte tendrá un periodo de seis meses para decidir. Si la Corte autoriza la celebración del referendo, la Registraduría tendrá que establecer su fecha. El referendo no podrá ocurrir en el mismo día de las elecciones legislativas, que están programadas para el mes de marzo.

\section{CONCLUSIONES}

Sin lugar a dudas, el 2008 fue un año con acontecimientos de gran trascendencia nacional. Primero, en cuanto al conflicto armado, fuimos testigos de importantes logros militares, que sin duda han afectado a las FARC y han mejorado la posición relativa del Estado.

44 Muchos de los congresistas renunciaron a su fuero legislaivo, porque si son juzgados como legisladores, son automáticamente juzgados por la Corte Suprema de Justicia, y no tienen segunda instancia de apelación. Si renunciaren a su fuero, deben ser juzgados por la Fiscalía en un proceso que tiene segunda instancia.

45 "Proyecto de reforma a la justicia fue retirado por el Gobierno" (15 de octubre de 2008). "Proyecto de reforma a la justicia fue retirado por el Gobierno". [En línea] http:/ / www.eltiempo.com/archivo/documento/CMS4602729 [Consulta: 20-04-2009].

46 Ver "Zancadilla al referendo", en Revista Semana (22 de noviembre del 2008)". [En línea]: http:/ / www.semana. com/noticias-nacion/zancadilla-referendo/117985.aspx [Consulta: 20-04-2009]. 
Igualmente, los resultados agregados siguen mostrando una reducción significativa de los niveles de violencia en el territorio nacional. Sin embargo, esta imagen contrasta con el panorama que resulta de los diversos escándalos por los descubrimientos de comportamientos delincuenciales de la fuerza pública. Por eso el 2009 será crucial para ver si la capacidad del Estado también sirve para hacer pagar a los responsables, y evitar que estos fenómenos se generalicen aún más en el ejército más grande de la región.

En materia política, la agenda legislativa sigue sufriendo los estragos de la llamada parapolítica, similar a lo ocurrido en el 2007, dando mayor ilustración de una de las peores crisis de la rama legislativa en la historia del país. El número de legisladores involucrados sigue en aumento, y como consecuencia se incrementa la inhabilidad del Congreso para discutir las políticas públicas que son necesarias para superar la crisis que este fenómeno ha generado. Por eso esperar que esta situación mejore antes de unas nuevas elecciones legislativas suena improbable, así como la posibilidad de ver legislación que prevenga que este fenómeno se dé nuevamente.

Finalmente, durante el 2008 la mayoría uribista demostró que está dispuesta a todo para proteger su supervivencia. La propuesta para una segunda reelección del Presidente Uribe (ya sea por acto legislativo o por el referendo) pone en juego en Colombia la alternación presidencial, requisito fundamental de las democracias presidenciales. Por ello será prioritario observar qué ocurre en las diferentes instancias institucionales -para ver si Colombia puede seguir considerándose una excepción en la región andina o si, por el contrario, convergió con ella-.

\section{REFERENCIAS}

Botero, Felipe. 2007. “Colombia: ¿democracia, paracracia o simplemente desgracia?”, en Revista de Ciencia Politica, Volumen Especial 2007, pp. 97-111.

Botero, Felipe y María Lucía Méndez. 2008. “¿Reír o llorar? El drama del conflicto y la resiliencia de la economía en Colombia, 2007", en Revista de Ciencia Política, Vol. 28, № 1, 2008, pp. 121-145.

Botero, Felipe y Juan Carlos Rodríguez. 2006. “Ordenando el caos. Elecciones legislativas y reforma electoral en Colombia", en Revista de Ciencia Política, Vol. 26, № 1, pp. 138-151.

Centro de Investigación y Educación Popular (CINEP). 2009. Informe Especial abril 2009 - Falsos Positivos: Balance del segundo semestre 2008. [En línea]: http:/ /www.cinep.org.co/sites/cinep.cinep.org.co/ files/Informe\%20falsos\%20positivos\%202008-II\%20-\%20Abril\%202009\%20_FINAL_.pdf, [Consulta: 20-04-2009].

Comisión Colombiana de Juristas. 2008. Informe para el examen periódico anual de Colombia. [En línea]: http:/ / www.coljuristas.org/archivos/infofinalepucol.pdf , [Consulta: 20-04-2009].

Congreso Visible. 2008. Boletín en Línea $\mathrm{N}^{\circ}$ 7: Balance Legislativo: Legislatura 2008-2009 periodo I. [En línea] http://cvisible.uniandes.edu.co/var/rw/CMS/novedadesBibliografica/Boletin\%20en $\% 20$ Linea/NUEVO!\%20Boletin\%20en\%20linea\%20No\%207/Boletin\%20en\%20linea\%20No\%207.pdf [Consulta: 20-04-2009].

Departamento Nacional de Planeación (DNP). 2008. Balance de Resultados Plan Nacional de Desarrollo "Estado Comunitario: Desarrollo para todos". [En línea]: http://www.dnp.gov.co/portalweb/gobierno/result adoseimpactodelagesti\%c3\%b3np\%c3\%bablica/tabid/99/default.aspx [Consulta: 20-04-2009].

International Monetary Fund (IMF). 2009. World Economic Outlook (WEO): Crisis and Recovery. [En línea] http://www.imf.org/external/pubs/ft/weo/2009/01/pdf/text.pdf [Consulta: 20-04-2009]. 
Fundación Ideas para la Paz (FIP). 2008. "Estadísticas sobre la Reinserción en Colombia". [En línea] http://www.ideaspaz.org/new_site/secciones/publicaciones/download_documentos/estadisticas_ reinsercion_colombia\%20(31\%20enero\%202008).pdf [Consulta: 20-04-2009].

Diario El Espectador ( 5 de marzo de 2009). "El problema de los falsos positivos ya fue resuelto: Mindefensa". [En línea] http:/ / www.elespectador.com/noticias/judicial/articulo124266-el-problema-de-los-falsospositivos-ya-fue-resuelto-mindefensa [Consulta: 20-04-2009].

Diario El Tiempo (19 de enero de 2009). “Tras renunciar al Congreso, senadora Gina Parody dice que también se va de la 'U'”. [En línea] http:/ / www.eltiempo.com/colombia/politica/senadora-gina-parodyanuncio-sorpresivamente-que-renunciara-al-congreso_4757017-1 [Consulta: 20-04-2009].

(26 de enero de 2008). "Nos daban cinco días de descanso por cada muerto". [En línea] http:// www.semana.com/noticias-nacion/daban-cinco-dias-descanso-cada-muerto/109046.aspx, [Consulta: 20-04-2009].

(29 de febrero del 2008). "Si el Presidente insiste en rescates militares va a recibir 40 o 50 cadáveres: Luis Eladio Pérez". [En línea]: http://www.eltiempo.com/archivo/documento/CMS-3979605 [Consulta: 20-04-2009].

(7 de marzo del 2008). "Gestos y anuncios en la Cumbre de Río que permitieron poner fin a la crisis". [En línea] http://www.eltiempo.com/archivo/documento/CMS-3992208 [Consulta: 20-04-2009].

(21 de marzo de 2008). "Entregué a más de 30 jóvenes para 'falsos positivos". [En línea] http:// www.semana.com/noticias-nacion/entregue-30-jovenes-para-falsos-positivos/121974.aspx, [Consulta: 20-04-2009].

(21 de abril de 2008). “La Violencia se ha Recrudecido en Sur de Bolívar y Magdalena Medio Rastro de Ex 'Para' Recién Fugado, Tras Amenazas de Bandas”. [En línea] http:/ /www.eltiempo. com/archivo/documento/MAM-2905988 [Consulta: 20-04-2009].

(3 de mayo de 2008). "Pelea de barrio". [En línea] http://www.semana.com/noticias-nacion/ pelea-barrio/111515.aspx [Consulta: 20-04-2009].

(14 de mayo de 2008). “¿Tras extradición de jefes paramilitares habrá verdad, justicia y reparación?". [En línea] http://www.eltiempo.com/archivo/documento/CMS-4163130 [Consulta: 20-04-2009].

(15 de mayo de 2008). "El Procurador reabre caso de Yidis Medina". [En línea] http://www. eltiempo.com/archivo/documento/MAM-2935808. [Consulta: 20-04-2009].

(25 de mayo de 2008). "Los fallos de la Corte son políticos y van contra del Presidente Uribe' El Senador Mauricio Pimiento". [En línea]: http://www.eltiempo.com/archivo/documento/MAM2949565. [Consulta: 20-04-2009].

(3 dejunio de 2008). "Reelección del Presidente Uribe sin los votos de Cambio Radical, no pasa", dice Elízabeth Ungar. [En línea]: http://www.eltiempo.com/archivo/documento/CMS-4232455. [Consulta: 20-04-2009].

. (27 de junio de 2008). “Condena A Yidis: Corte Suprema Cuestiona Aprobación De Reelección”. [En línea] http:/ /www.eltiempo.com/archivo/documento/MAM-2991839. [Consulta: 20-04-2009].

. (3 de julio de 2008). "Con Engaño de Caballo de Troya, Ejército Rescató a los 15 Rehenes". [En línea]: http:/ /www.eltiempo.com/archivo/documento/MAM-2999143. [Consulta: 20-04-2009]. (6 de septiembre de 2008). “QQué mamera!". [En línea] http:/ / www.semana.com/noticias-nacion/ mamera/115253.aspx. [Consulta: 20-04-2009].

(15 de octubre de 2008). "Proyecto de reforma a la justicia fue retirado por el Gobierno". [En línea] http://www.eltiempo.com/archivo/documento/CMS-4602729. [Consulta: 20-04-2009].

(14 de noviembre de 2008). "La historia de DRFE, la pirámide que puso a temblar a 11 departamentos". [En línea] http://www.eltiempo.com/archivo/documento/CMS-4664899. [Consulta: 20-04-2009]. Revista Semana (17 de abril del 2008). "Al país no le conviene regresar al Frente Nacional": David Luna". [En línea] http://www.semana.com/noticias-on-line/pais-no-conviene-regresar-frente-nacionaldavid-luna/111059.aspx. [Consulta: 20-04-2009].

(27 de octubre de 2008). "El descontrol de las FARC". [En línea] http://www.semana.com/ noticias-conflicto-armado/descontrol-farc/117129.aspx. [Consulta: 20-04-2009]. 
(22 de noviembre de 2008). "Zancadilla al referendo". [En línea] http://www.semana.com/ noticias-nacion/zancadilla-referendo/117985.aspx. [Consulta: 20-04-2009].

Shugart Matthew, Erika Moreno, and Luis E. Fajardo. 2006. “Deepening Democracy by Renovating Political Practices: The Struggle for Electoral Reform in Colombia". En Peace, Democracy, and Human Rights in Colombia. Notre Dame: University of Notre Dame (páginas del capítulo).

Mónica Pachón es profesora asistente del Departamento de Ciencia Política de la Universidad de los Andes, en Bogotá, Colombia. Tiene una maestría en Estudios Latinoamericanos de la Universidad de Oxford y un PhD en Ciencia Política de la Universidad de California, San Diego. Su investigación se centra principalmente en las relaciones Ejecutivo-Legislativo en regímenes presidenciales.

[E-mail: mopachon@uniandes.edu.co] 


\section{ANEXO 1}

Gráfica 5: Número de víctimas y masacres, 2002 - 2008.

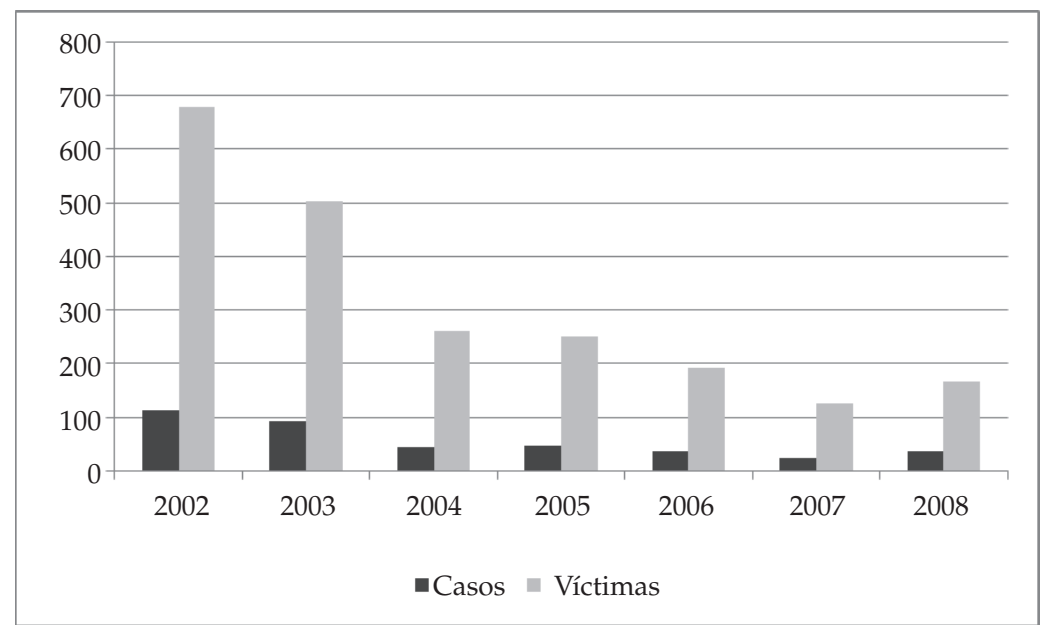

Fuente: Ministerio de Defensa.

Gráfica 6: Número de homicidios, 2002 - 1998

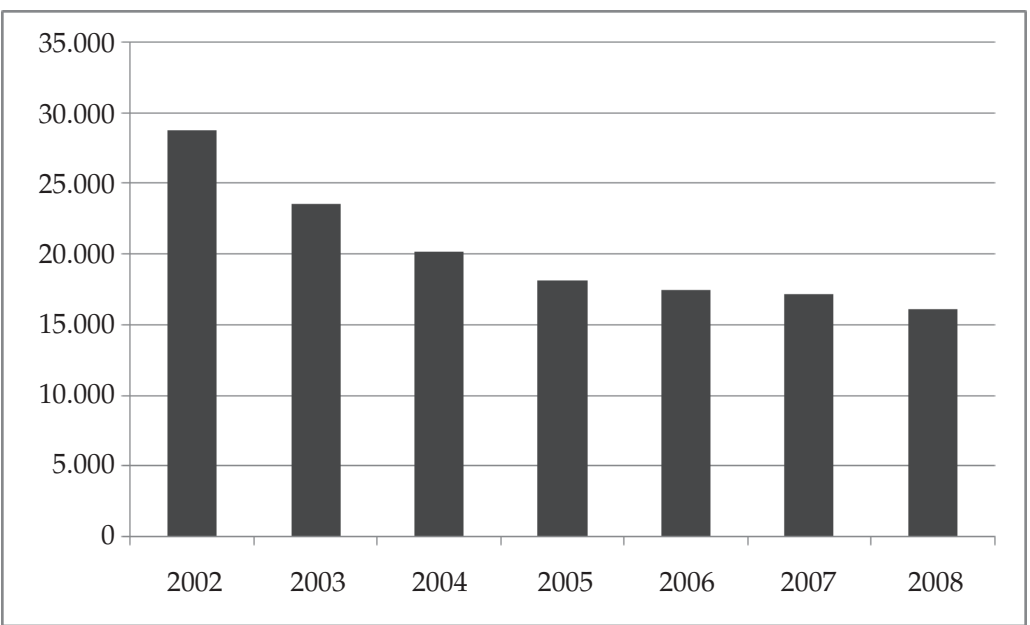

Fuente: Ministerio de Defensa. 


\section{ANEXO 2. GABINETE}

Ministerio del Interior: Carlos Holguín Sardi (1940 masculino, Partido Conservador), nombrado el 7 agosto 2006. Renuncia en mayo para ser reemplazado por Fabio Valencia Cossio el 20 de junio del 2008 (1948, masculino, Partido Conservador).

Ministerio de Hacienda: Óscar Iván Zuluaga (1957, Masculino, Partido de la 'U') nombrado el 16 febrero 2007.

Ministerio de Defensa: Juan Manuel Santos (1950 masculino, Partido de la 'U') nombrado el 7 agosto 2006.

Ministerio de Relaciones Exteriores: Fernando Araújo (1955 masculino, Partido Conservador) nombrado en febrero de 2007, reemplazado por Jaime Bermúdez (1966 masculino, uribista-independiente)* en julio del 2008.

Ministerio de Protección Social: Diego Palacio Betancourt (1961 masculino, uribistaindependiente)* ratificado en su cargo.

Ministerio de Agricultura y Desarrollo Rural: Andrés Felipe Arias (1973 masculino, Partido Conservador) ratificado en su cargo en agosto del 2006. Reemplazado por Andrés Fernández Acosta (masculino, uribista-independiente) en agosto 2008.

Ministerio Medio Ambiente, Vivienda y Desarrollo Territorial: Juan Francisco Lozano (1964 masculino, Cambio Radical) nombrado en 5 julio 2006.

Ministerio de Comercio, Industria y Turismo: Luis Guillermo Plata (1971 masculino, uribista-independiente)** nombrado el 16 de enero del 2007.

Ministerio de Comunicaciones: María del Rosario Guerra (1961 femenino, Partido Liberal) nombrada el 7 agosto 2006.

Ministerio de Cultura: Paula Marcela Moreno (femenino, independiente) nombrada el 11 de mayo del 2007.

Ministro de Minas y Energías: Hernán Martínez Torres (1941 masculino, Partido Conservador) nombrado el 7 agosto 2006.

Ministerio de Educación Nacional: Cecilia María Vélez White (1952 femenino, uribistaindependiente)* ratificada en su cargo el 7 de agosto del 2006.

Ministerio de Transporte: Andrés Uriel Gallego (1950 masculino, uribista-independiente)* ratificado en su cargo el 7 de agosto del 2006.

* Los uribistas-independientes son personas sin filiación partidista pero con afinidad ideológica con Uribe. 


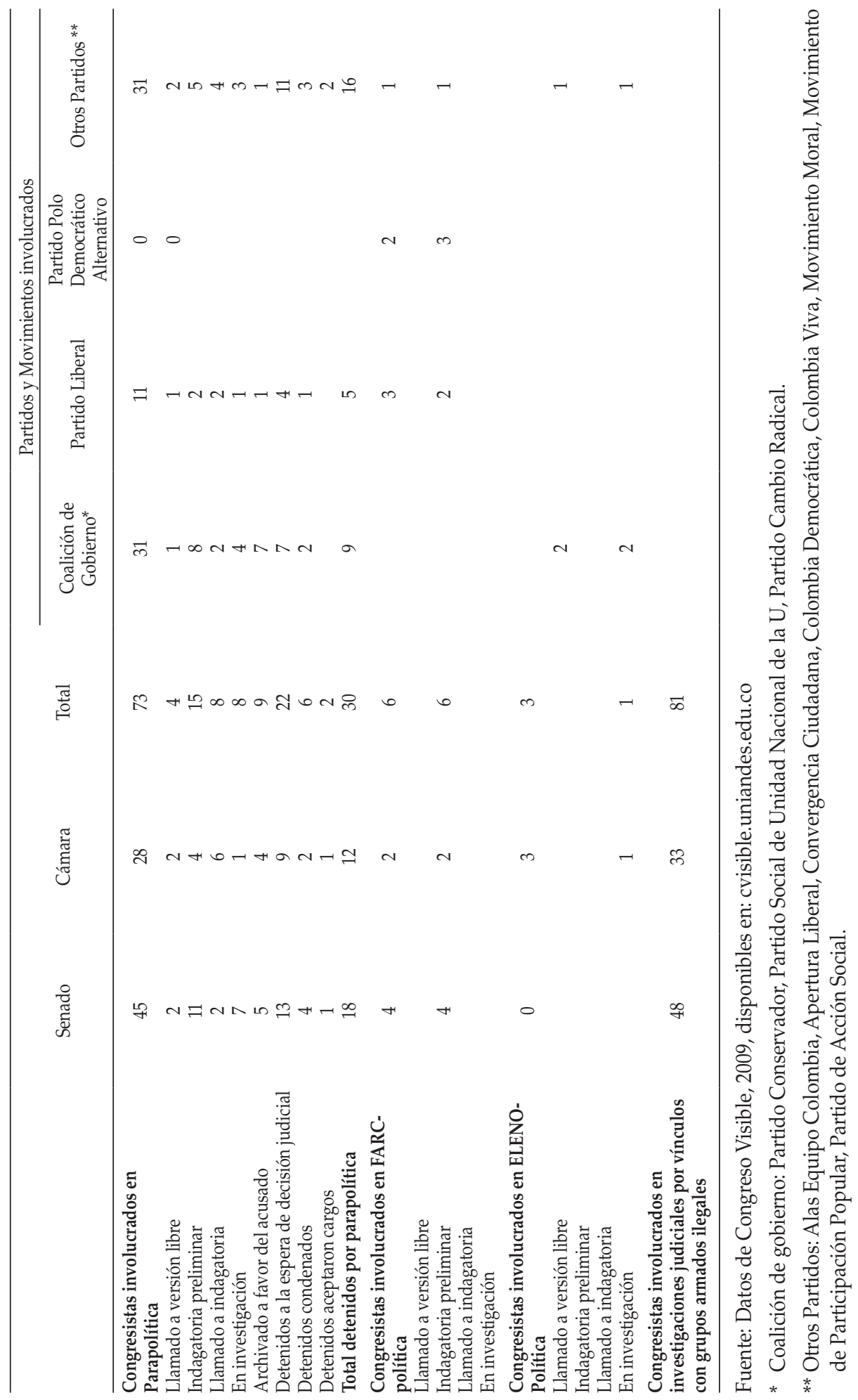


